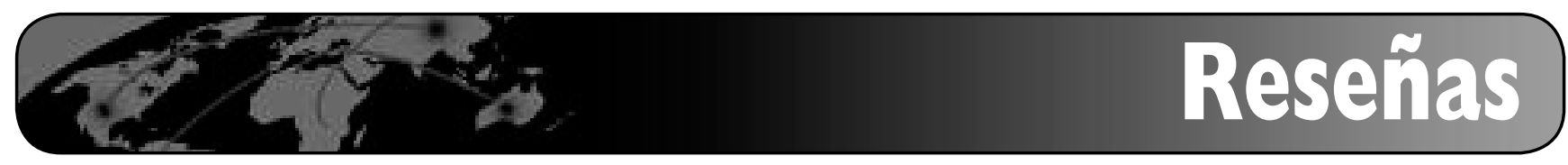

\title{
Biblioteca universitaria, crai y alfabetización informacional (María Pinto, Dora Sales y Pilar Osorio)
}

\author{
Por Concepción Rodríguez-Parada
}

Rodríguez-Parada, Concepción. "Biblioteca universitaria, crai y alfabetización informacional (María Pinto, Dora Sales y Pilar Osorio)". En: El profesional de la información, 2008, mayo-junio, v. 17, n. 3, pp. 359-360.

DOI: 10.3145/epi.2008.may.14

DURANTE LA CELEBRACIÓN EN LA UNIVERSITAT DE BARCELONA (marzo de 2008) de la Conferencia de primavera de la EUA (European University Association), se ha definido la estrategia a seguir para consolidar los retos del EEES (Espacio Europeo de Educación Superior) y del EEI (Espacio Europeo de Investigación).

El libro que reseñamos se ocupa precisamente de la consecución de los objetivos que plantean ambos proyectos, que requieren la participación activa de la biblioteca concebida como taller o laboratorio, porque enseña a "aprender a buscar y construir conocimiento" (p. 93), y como corazón, por la importancia de las funciones y tareas que en ella se desarrollan para que la universidad consiga sus objetivos.

El protagonismo de la biblioteca universitaria en este proceso como centro facilitador de recursos para el aprendizaje y la investigación, se hace visible a través del cambio de nombre (crai o centro de recursos para el aprendizaje y la investiga- ción). La nueva denominación va más allá de un simple maquillaje por cuanto exige la siempre difícil convergencia de servicios (bibliotecarios, educativos, editoriales e informáticos) para acometer las funciones requeridas por la nueva universidad surgida de Bolonia, mejor y más competitiva, y bastión de la Europa del conocimiento. Una de estas funciones es la alfabetización informacional (alfin), auténtica "competencia transversal en la sociedad del conocimiento" (p. 89).

En el contexto descrito hay que situar la obra de Pinto, Sales y Osorio. Con una clara intención didáctica, las autoras exponen en una secuencia coherente y explicativa en sí misma, desde los prolegómenos (cap. 1) que confluyen en el EEES (cap. 2), pasando por la necesaria gestión del cambio de biblioteca a crai (cap. 3), el papel de éste ante el paradigma de la alfin (cap. 4), como apoyo a la docencia, al aprendizaje y a la actividad investigadora (cap. 5), para finalizar con ejemplos de buenas prácticas de alfabetización informacional de universidades nacionales y extranjeras (cap. 6), que

\section{Pinto, María; Sales, Dora; Osorio, Pilar. Biblioteca universitaria, CRAl y alfabetización informacional. Gijón: Trea, 2008. 245 p. (Biblioteca y administración cultural; 179).}

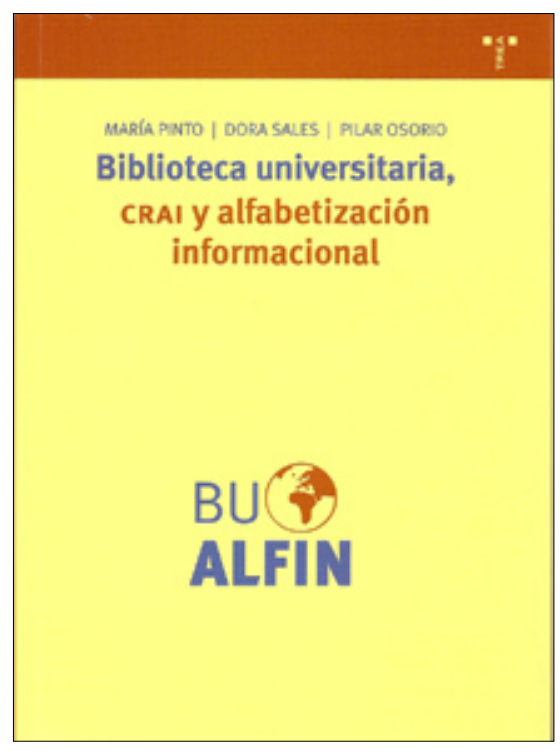

han de permitir planificar poner en marcha y evaluar más programas desde el crai (cap. 7).

A pesar de que crai y alfin tienen una propuesta de máximos, es posible añadirles ciertas dosis de realidad a escala humana, de tal manera que pueda darse una diversidad de planteamientos con "un mínimo común denominador" según la universidad de la que se trate: "el crai no es una imposición, es una opción que cada universidad debe adaptar a su filosofía, a sus necesidades y a sus posibilidades. Es un proyecto de largo recorrido, que implica una actitud proactiva de los servicios convergidos y que irá madurando en su andadura con la implementación y evaluación de proyectos y servicios" (p. 81). 
"A pesar de que crai y alfin tienen una propuesta de máximos, es posible añadirles ciertas dosis de realidad a escala humana"

La finalidad del libro responde ampliamente al nombre de la colección en la que se publica: "Biblioteca y administración cultural", por cuanto se dirige al personal de los servicios llamados a converger. Explica de manera certera los cambios a los que se ve sometida la biblioteca en el proceso de transformación a crai y el nuevo y esperanzador horizonte que se abre ante él.

Con todo, más importante aún es su utilidad para los equipos rectorales y gestores de la universidad que, más preocupados por la modificación de planes de estudio, la elaboración de planes estratégicos, la definición de nuevas estructuras de gobierno y de nuevas fuentes financiación, quizá desconozcan el papel nuclear del crai en el EEES y el EEI. Al ser adecuado para ambos colectivos, este libro debe servir para aclarar malentendidos y "establecer alianzas, fomentar sinergias $\mathrm{y}$ tender puentes para iniciar proyectos y acciones colaborativas" (p. 16) entre ellos.

Un valor añadido de la obra que comentamos es que se trata de un libro que incorpora "argumentos de autoridad". Esto es, las autoras se sirven de su conocimiento y experiencia sobre el tema, ampliamente reconocidos en el caso de María Pinto, y aportan además opiniones de expertos, directrices elaboradas por varias organizaciones internacionales y numerosas muestras de buenas prácticas que, convenientemente analizadas, enmarcan y corroboran el objetivo de las autoras. Éste no es otro que mostrar que el "reto abierto" de formar "equipos interdisciplinares" para "avanzar hacia una auténtica universidad alfabetizada en información es un desafío que hay que convertir en oportunidad y fortaleza desde la fase embrionaria en que nos hallamos" (p. 222) no sólo es posible, sino que resulta imprescindible.

http://www.mariapinto.es/alfineees/AlfinEEES.htm

Por todo ello esta obra debería ser de obligada lectura para quienes participen en los procesos que lleven al crai a convertirse en ese elemento clave para que los miembros de la comunidad universitaria "aprendan a aprender" y que "este aprendizaje [se produzca] a lo largo de la vida" (pp. 202-203).

El libro se complementa con una bibliografía seleccionada, direcciones electrónicas de interés y un glosario de términos relacionados que permiten a los lectores poner en práctica el meta-aprendizaje (p. 241).

\section{Concepción Rodríguez-Parada, Departament de Biblioteconomia $i$ Documentació, Universitat de Bar- celona. \\ crodriguezp@ub.edu}

- Anuario ThinkEPI 2008

- Anuario ThinkEPI 2007

- Anuario ThinkEPI $2007+2008$
Institución 93€
Institución $30 €$
Individual particular $35 €$
Institución $120 €$

Apellidos:

Empresa:

Calle:

CP:

Ciudad:

Email:
Nombre:

NIF:

Número:

Piso:

Provincia:

Teléfono:

Marque con una cruz la forma de pago elegida:

Ingreso o transferencia bancaria a la cuenta de La Caixa 21000818930200745544

Cheque enviado al apartado de correos 32.280, 08080 Barcelona

Tarjeta de crédito número: $-$ $-$ (caduca $\longrightarrow$ 